\title{
Single-Molecule Magnet with Thermally Activated Delayed Fluorescence Based on a Metallofullerene Integrated by Dysprosium and Yttrium Ions
}

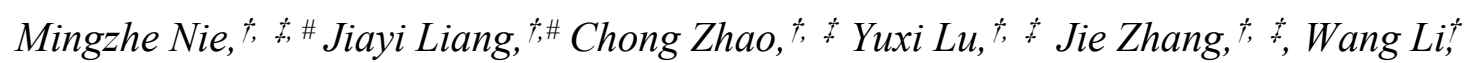
, * Chunru Wang, ${ }^{\dagger}$ Taishan Wang ${ }^{\dagger *}$

'Beijing National Laboratory for Molecular Sciences, Key Laboratory of Molecular Nanostructure and Nanotechnology, Institute of Chemistry, Chinese Academy of Sciences, Beijing 100190, China

University of Chinese Academy of Sciences, Beijing 100049, China

\#These authors contributed equally

Corresponding Author: wangtais@iccas.ac.cn (T. Wang)

\section{Experimental methods}

Synthesis and characterization. $\mathrm{DyY}_{2} \mathrm{~N} @ \mathrm{C}_{80}$ and $\mathrm{Y}_{3} \mathrm{~N} @ \mathrm{C}_{80}$ were synthesized by arc-discharging method, the mixture of graphite powder and metal alloy (for $\mathrm{DyY}_{2} \mathrm{~N} @ \mathrm{C}_{80}$, molar ratio of Dy/Ni: $\mathrm{Y} / \mathrm{Ni}$ alloy=3: 1 , for $\mathrm{Y}_{3} \mathrm{~N} @ \mathrm{C}_{80}$, molar ratio of $\mathrm{Y} / \mathrm{Ni}: \mathrm{C}=3: 1$ ) were encapsulated into core-drilled graphite rods. Subsequently, the mixed rods were vaporized in a Krätschmer-Huffman generator under an atmosphere of 6 Torr $\mathrm{N}_{2}$ and 194 Torr He. The as-prepared soot was first Soxlet-extracted with toluene for $24 \mathrm{~h}$, and then the concentrated toluene solution was filtered and subjected for HPLC purification, the isolation was accomplished by multistep HPLC. The purity was determined by high resolution matrix-assisted laser desorption ionization time-of-flight (MALDI-TOF) mass spectrum (Autoflex, Bruker). UV-vis-NIR spectrum was collected with toluene solution (Lambda 950, PerkinElmer). [12]CPP is purchased from J\&K, $\mathrm{DyY}_{2} \mathrm{~N} @ \mathrm{C}_{80} \subset[12] \mathrm{CPP}$ and $\mathrm{Y}_{3} \mathrm{~N} @ \mathrm{C}_{80} \subset[12] \mathrm{CPP}$ were synthesized by mixing Dy ${ }_{2} \mathrm{~N} @ \mathrm{C}_{80} /$ $\mathrm{Y}_{3} \mathrm{~N} @ \mathrm{C}_{80}$ with [12]CPP in toluene with 1:1 molar ratio at room temperature, the supramolecular complex was verified by MALDI-TOF mass spectrum (Autoflex, Bruker). 
Magnetic measurements. Magnetic properties were determined using Quantum Design MPMS3 VSM magnetometer. The sample was prepared by drop-casting Dy ${ }_{2} \mathrm{~N} @ \mathrm{C}_{80}$ carbon disulfide solution onto a slice of $\mathrm{Al}$ foil, black $\mathrm{DyY}_{2} \mathrm{~N} @ \mathrm{C}_{80}$ powders were obtained after evaporation of carbon disulfide. Then the Al foil was folded into a small cube with black Dy ${ }_{2} \mathrm{~N} @ \mathrm{C}_{80}$ powders packaged in it. Finally, the cube was fixed on the wall of a straw with very small amount of M grease. The mass of $\mathrm{DyY}_{2} \mathrm{~N} @ \mathrm{C}_{80}$ was $0.53 \mathrm{mg}$, while that of $\mathrm{Al}$ foil was $0.9 \mathrm{mg}$. Al foil and molecular formula (Pascal constant) were evaluated when data correction was carried out. The M grease was not evaluated as the mass of it was hard to be determined. The data of magnetic hysteresis and ZFC/FC were collected using VSM mode, while the other data were collected using dc mode. In magnetization decay experiments, a field of 10000 Oe was applied to magnetize the samples and then set at 2000 Oe to record the decay of magnetization. The relaxation times were obtained by fitting the data using equation $\mathrm{S} 1$, where $M_{\mathrm{eq}}, \tau$ and $\mathrm{b}$ are fitting parameters.

$$
M(\mathrm{t})=M_{\mathrm{eq}}+\left(M_{0}-M_{\mathrm{eq}}\right) \exp \left[-(t / \tau)^{b}\right]
$$

Photoluminescence measurements. Temperature-dependent steady-state photoluminescence (PL) spectra were recorded on FLS980 (Edinburgh Instrument, UK) equipped with R298-P PMT $(200-900 \mathrm{~nm})$, the excitation source is a Xenon lamp. The excitation wavelength was set at 405 nm for DyY $\mathrm{Y}_{2} \mathrm{~N} @ \mathrm{C}_{80}, \mathrm{Y}_{3} \mathrm{~N} @ \mathrm{C}_{80}, \mathrm{Dy}_{2} \mathrm{~N} @ \mathrm{C}_{80} \subset[12] \mathrm{CPP}$ and $\mathrm{Y}_{3} \mathrm{~N} @ \mathrm{C}_{80} \subset[12] \mathrm{CPP}$ dispersed in degassed polystyrene film, and was set at $350 \mathrm{~nm}$ for [12]CPP $\left(\mathrm{DyY}_{2} \mathrm{~N} @ \mathrm{C}_{80} \subset[12] \mathrm{CPP}\right.$ and $\mathrm{Y}_{3} \mathrm{~N} @ \mathrm{C}_{80} \subset[12] \mathrm{CPP}$ degassed films), respectively. The absolute photoluminescence quantum yields (QY) of DyY ${ }_{2} \mathrm{~N} @ \mathrm{C}_{80}$ and $\mathrm{Y}_{3} \mathrm{~N} @ \mathrm{C}_{80}$ degassed polystyrene films were measured with an integrating sphere. PL lifetimes of $\mathrm{DyY}_{2} \mathrm{~N} @ \mathrm{C}_{80}$ and $\mathrm{Y}_{3} \mathrm{~N} @ \mathrm{C}_{80}$ degassed polystyrene films were measured using a microsecond flash-lamp as excitation source at $80 \mathrm{~K}$ (excitation wavelength is $405 \mathrm{~nm}$ ), and were measured using a VPL laser as excitation source from $100 \mathrm{~K}$ to $300 \mathrm{~K}$ (excitation wavelength is $405 \mathrm{~nm}$, frequency is ranging from $5 \mathrm{~Hz}$ to $5 \mathrm{kHz}$, pulse width is ranging from $1 \mu \mathrm{s}$ to $2 \mu \mathrm{s})$. The nanosecond PL lifetimes of $\mathrm{DyY}_{2} \mathrm{~N} @ \mathrm{C}_{80}$ and $\mathrm{Y}_{3} \mathrm{~N} @ \mathrm{C}_{80}$ degassed polystyrene films were measured using a EPL laser as excitation source from $80 \mathrm{~K}$ to $300 \mathrm{~K}$ (excitation wavelength is $405 \mathrm{~nm}$, frequency is $2 \mathrm{MHz}$, pulse width is $500 \mathrm{~ns}$ ). 
(a)

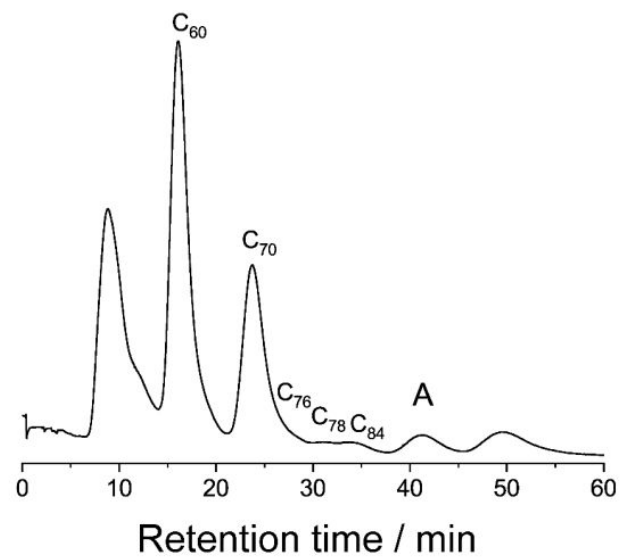

(b)

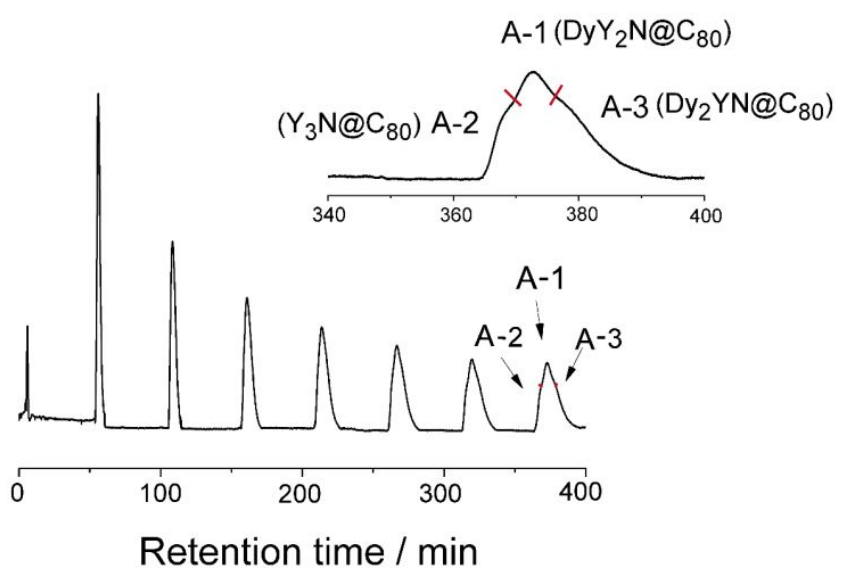

(c)

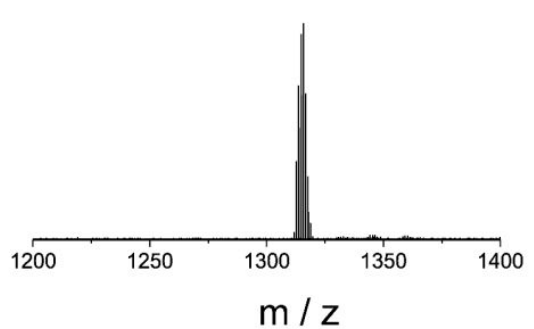

Figure S1. (a) HPLC profile of extract mixtures from raw soot with a $20 \times 250 \mathrm{~mm}$ Buckyprep column, $12 \mathrm{~mL} / \mathrm{min}$ flow rate with toluene as eluent phase. Fraction A was collected. (b) Recycling HPLC profile of fraction A in a $20 \times 250 \mathrm{~mm}$ Buckyprep column, $6 \mathrm{~mL} / \mathrm{min}$ flow rate with toluene as eluent phase. Fraction A-1 was collected. Inset showed the peak cutting point in the separation process. We cut the HPLC peaks and collected the A-1 fraction to purify the compound. Moreover, the collected fraction A-1 was further subjected to HPLC and purified again by recycling method. The cutting process was repeated until we obtain very pure product of $\mathrm{DyY}_{2} \mathrm{~N} @ \mathrm{C}_{80}$ as characterized by mass spectrometry. (c) Enlarged MALDI-TOF mass spectrum ranging from 1200-1400. 


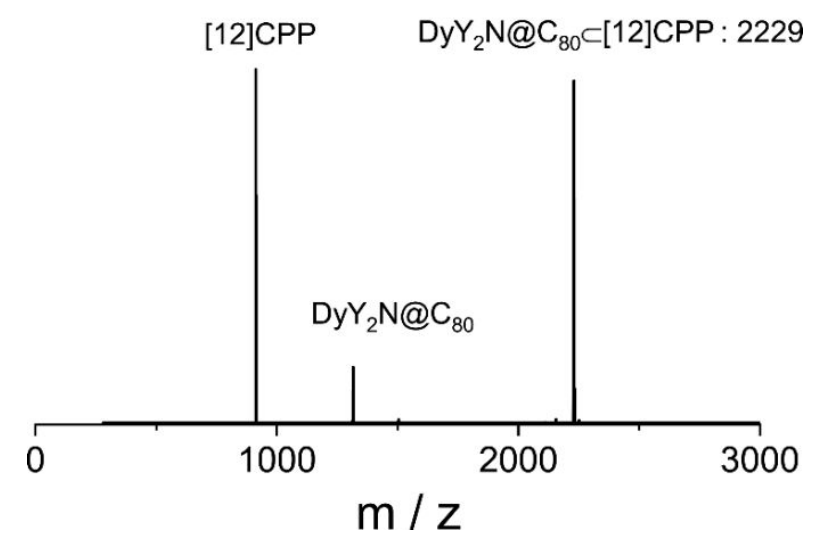

Figure S2. MALDI-TOF mass spectrum of $\mathrm{DyY}_{2} \mathrm{~N} @ \mathrm{C}_{80} \subset[12] \mathrm{CPP}$.

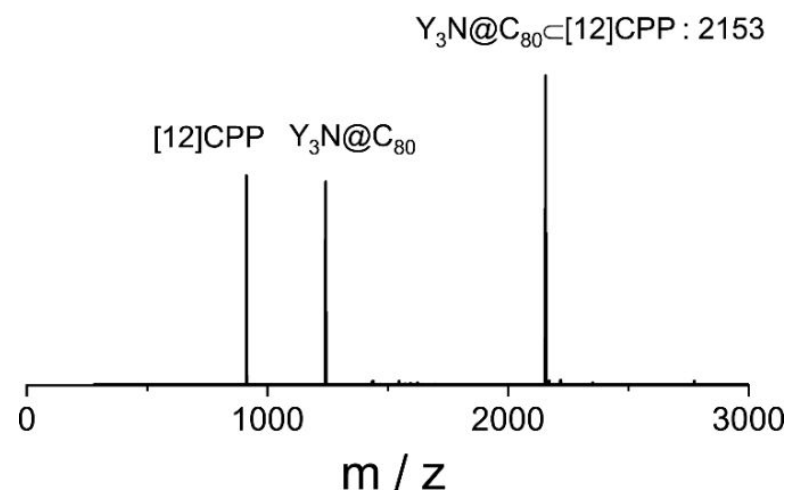

Figure S3. MALDI-TOF mass spectrum of $\mathrm{Y}_{3} \mathrm{~N} @ \mathrm{C}_{80} \subset[12] \mathrm{CPP}$.

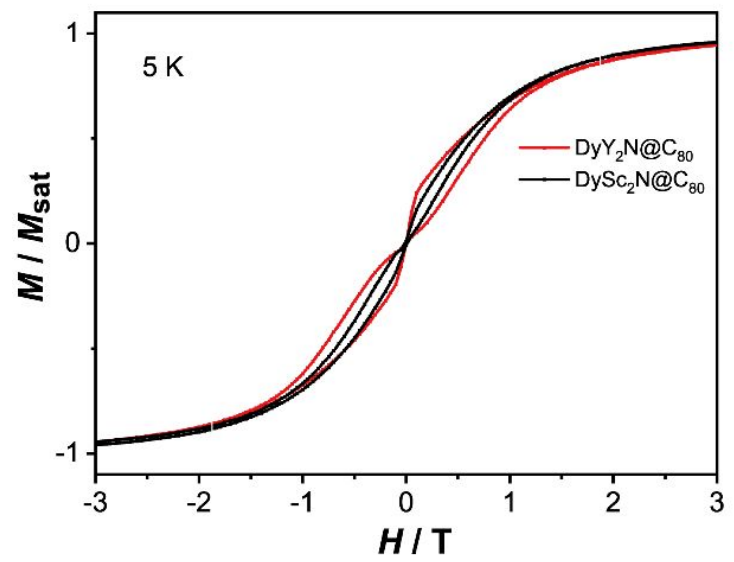

Figure S4. Plots of magnetization vs applied magnetic field for DyY ${ }_{2} \mathrm{~N} @ \mathrm{C}_{80}$ and $\mathrm{DySc}_{2} \mathrm{~N} @ \mathrm{C}_{80}$ measured at $5 \mathrm{~K}$ (magnetic field sweeping rate of $330 \mathrm{Oe} \mathrm{s}^{-1}$ ). 


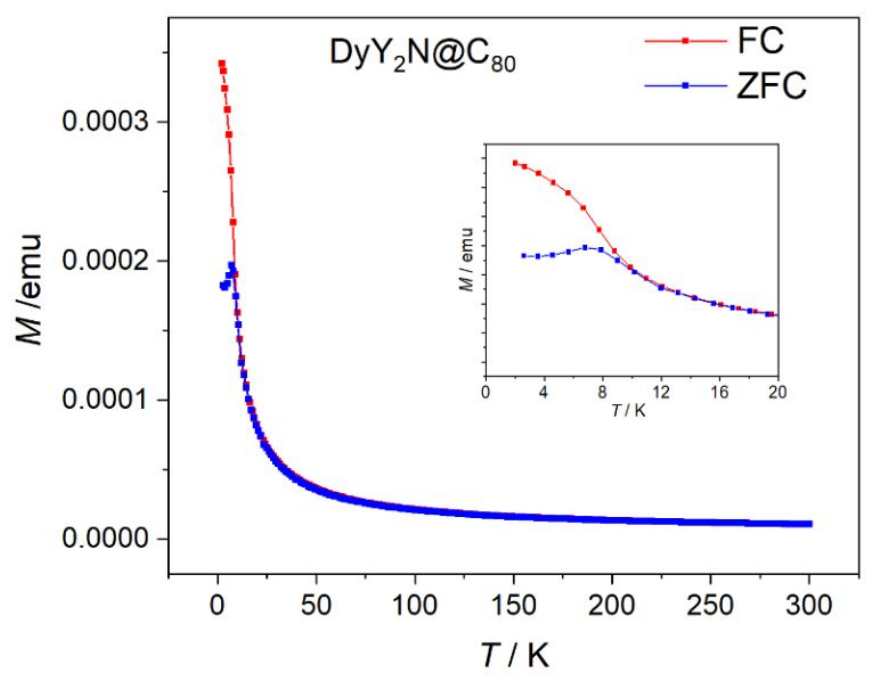

Figure S5. Plots of zero-field cooled (ZFC) and field cooled (FC) magnetization of $\mathrm{DyY}_{2} \mathrm{~N} @ \mathrm{C}_{80}$ $\left(1 \mathrm{kOe}, 3 \mathrm{~K} \cdot \mathrm{min}^{-1}\right)$.

(a)

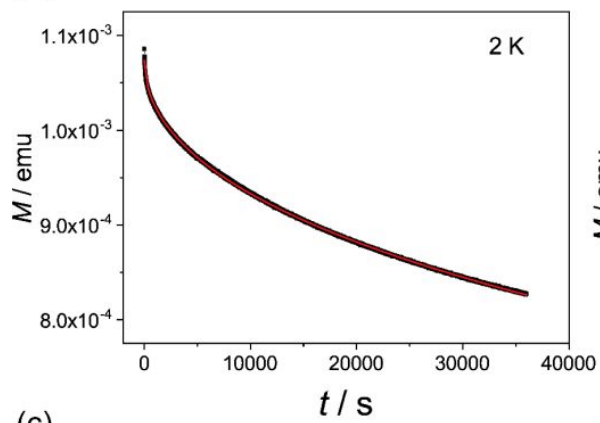

(c)

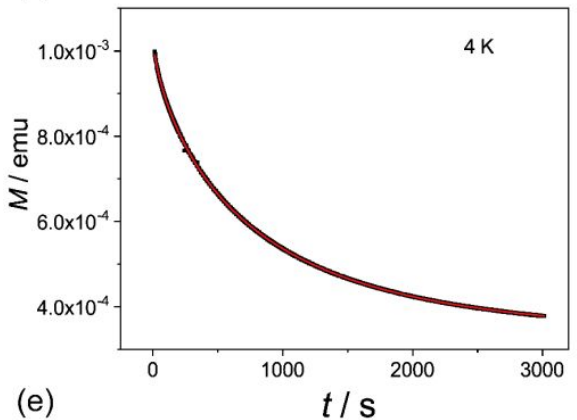

(e)

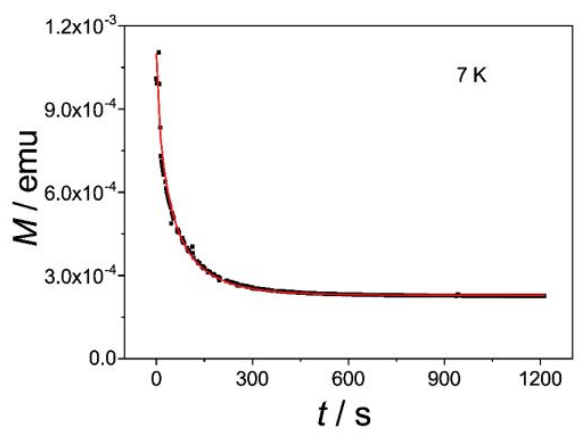

(b)

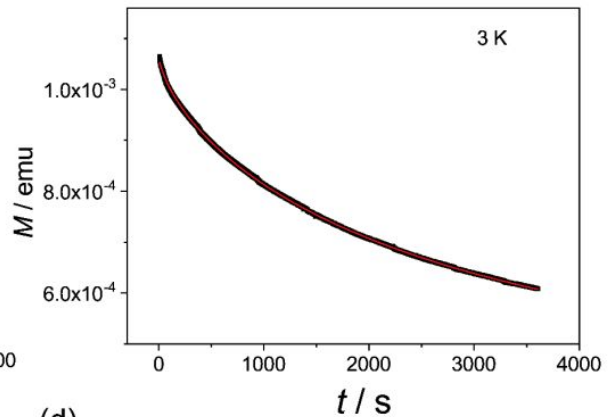

(d)

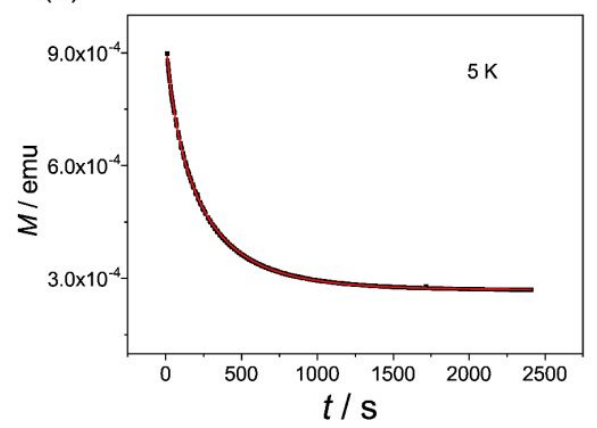

Figure S6. (a-e) Time dependent magnetization decay curves (black dot) and fitted curves (red line) for $\mathrm{DyY}_{2} \mathrm{~N} @ \mathrm{C}_{80}$ from 2 to $7 \mathrm{~K}$ under $0.2 \mathrm{~T}$. 
Table S1. The relaxation times of $\mathrm{DyY}_{2} \mathrm{~N} @ \mathrm{C}_{80}$ obtained by fitting the plots of time dependent magnetization decay, $M_{\mathrm{eq}}, \tau$ and $\mathrm{b}$ are fitting parameters.

\begin{tabular}{ccccccccc}
\hline$T / \mathrm{K}$ & $M_{\mathrm{eq}}$ & Error & $M_{0}$ & Error & $\tau / \mathrm{s}$ & Error & $b$ & Error \\
\hline 2 & $9.45 \mathrm{E}-5$ & $\pm 3.13 \mathrm{E}-7$ & $1.07 \mathrm{E}-3$ & $\pm 2.14 \mathrm{E}-7$ & 703071.5 & \pm 5046.5 & 0.48 & \pm 0.002 \\
3 & $4.05 \mathrm{E}-4$ & $\pm 5.98 \mathrm{E}-6$ & $1.06 \mathrm{E}-3$ & $\pm 9.06 \mathrm{E}-7$ & 2852.1 & \pm 58.9 & 0.70 & \pm 0.004 \\
4 & $3.35 \mathrm{E}-4$ & $\pm 2.72 \mathrm{E}-7$ & $1.03 \mathrm{E}-3$ & $\pm 3.59 \mathrm{E}-7$ & 748.9 & \pm 0.64 & 0.73 & \pm 0.0008 \\
5 & $2.70 \mathrm{E}-4$ & $\pm 1.52 \mathrm{E}-7$ & $9.61 \mathrm{E}-4$ & $\pm 1.35 \mathrm{E}-6$ & 201.7 & \pm 0.65 & 0.75 & \pm 0.002 \\
7 & $2.29 \mathrm{E}-4$ & $\pm 1.43 \mathrm{E}-6$ & $1.1 \mathrm{E}-3$ & $\pm 1.53 \mathrm{E}-5$ & 45.2 & \pm 1.53 & 0.67 & \pm 0.017 \\
\hline
\end{tabular}

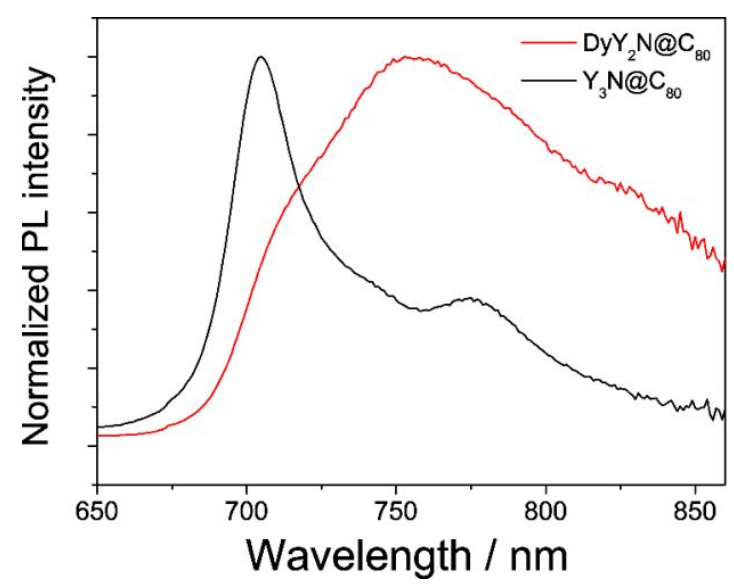

Figure S7. Photoluminescence spectra of $\mathrm{Dy}_{2} \mathrm{~N} @ \mathrm{C}_{80}$ and $\mathrm{Y}_{3} \mathrm{~N} @ \mathrm{C}_{80}$ dispersed in polystyrene film at $300 \mathrm{~K}\left(\lambda_{\mathrm{ex}}=405 \mathrm{~nm}\right)$.

(a)

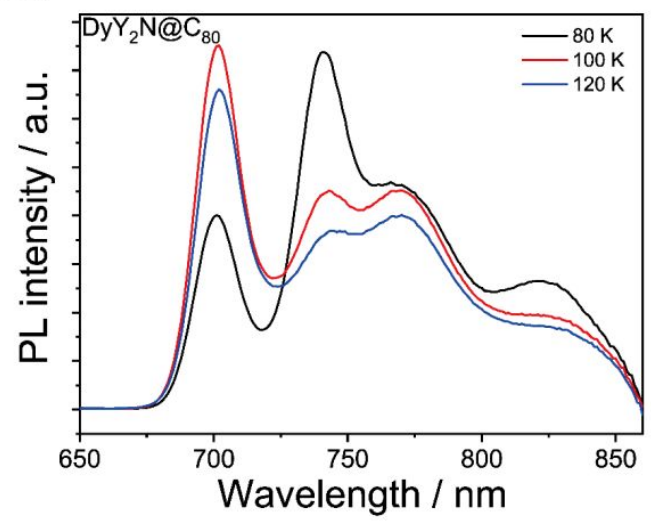

(b)

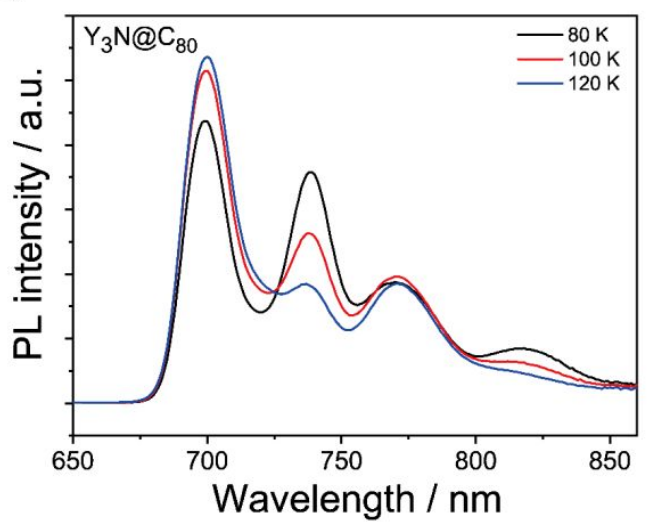

Figure S8. Photoluminescence spectra of $\mathrm{Dy}_{2} \mathrm{~N} @ \mathrm{C}_{80}$ and $\mathrm{Y}_{3} \mathrm{~N} @ \mathrm{C}_{80}$ dispersed in degassed polystyrene film at 80,100 and $120 \mathrm{~K}\left(\lambda_{\mathrm{ex}}=405 \mathrm{~nm}\right)$. 
(a)

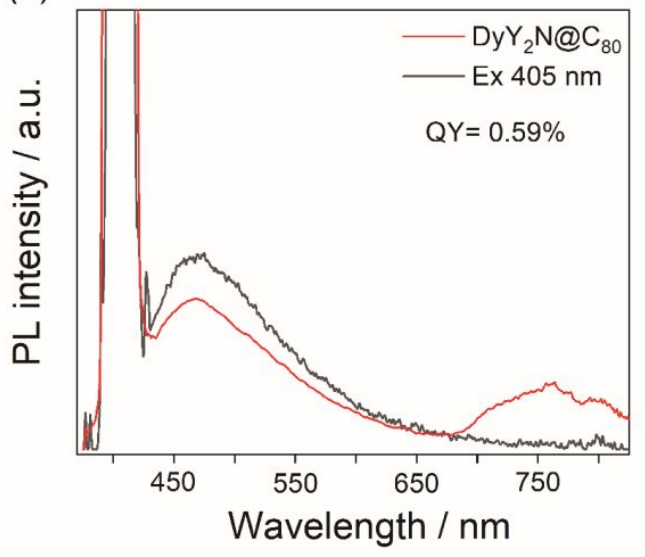

(b)

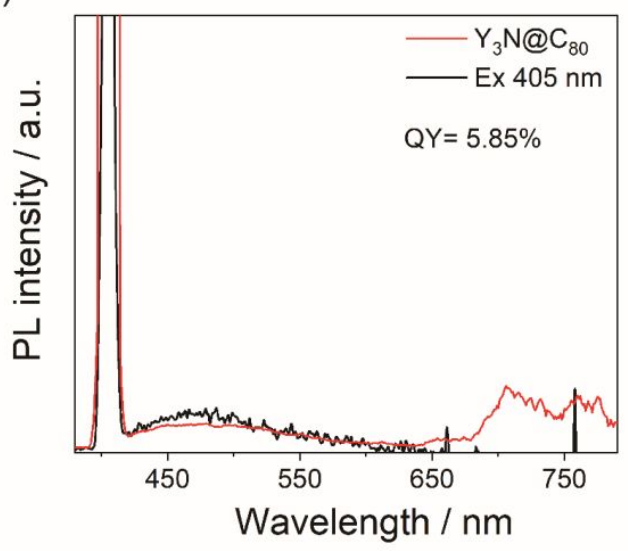

Figure S9. Quantum yields of $\mathrm{DyY}_{2} \mathrm{~N} @ \mathrm{C}_{80}$ and $\mathrm{Y}_{3} \mathrm{~N} @ \mathrm{C}_{80}$ dispersed in polystyrene film at room temperature $\left(\lambda_{\mathrm{ex}}=405 \mathrm{~nm}\right)$.

(a)

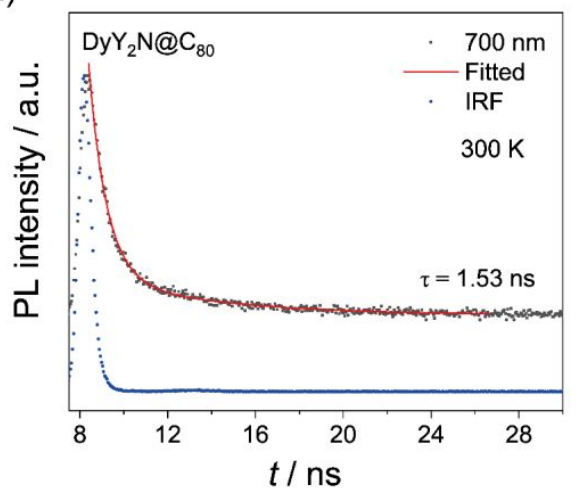

(c)

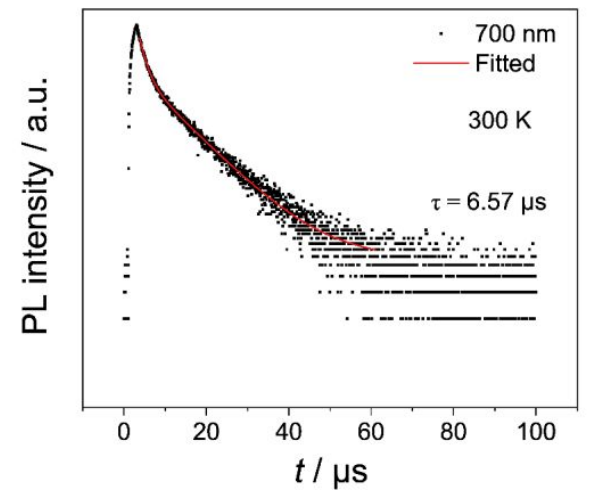

(b)

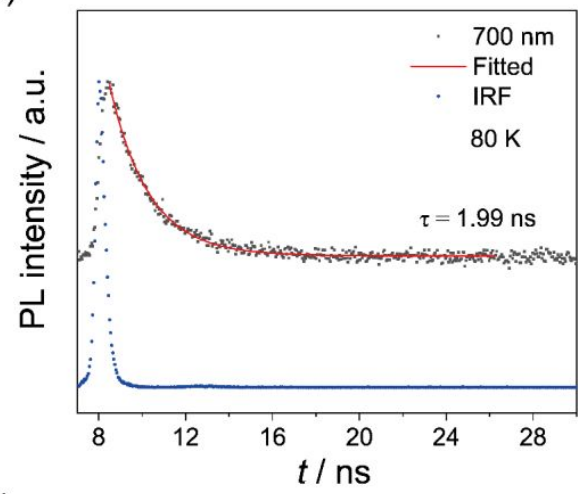

(d)

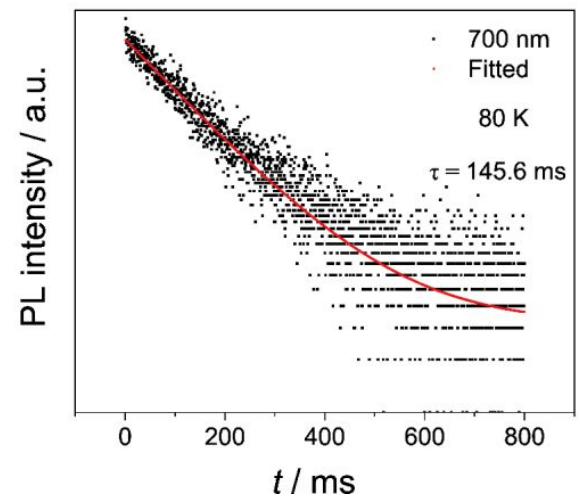

Figure S10. PL decay curves and fitted curves of emission peaks near $700 \mathrm{~nm}$ of $\mathrm{DyY}_{2} \mathrm{~N} @ \mathrm{C}_{80}$ at (a) $300 \mathrm{~K}$ and (b) $80 \mathrm{~K}$ for prompt lifetime, as well as emission peaks near $700 \mathrm{~nm}$ of $\mathrm{DyY}_{2} \mathrm{~N} @ \mathrm{C}_{80}$ at (c) $300 \mathrm{~K}$ and (d) $80 \mathrm{~K}$ for delayed lifetime. 
(a)

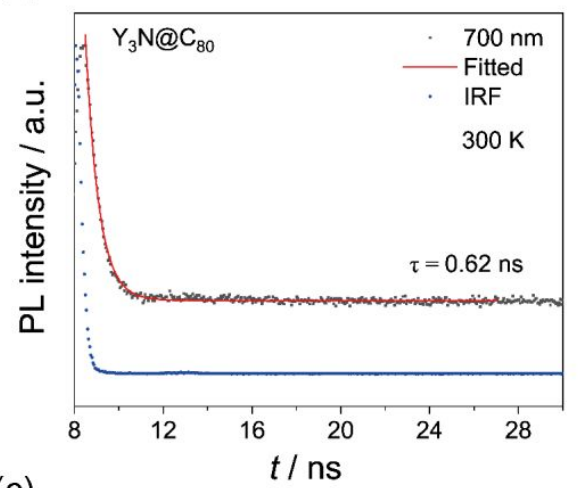

(c)

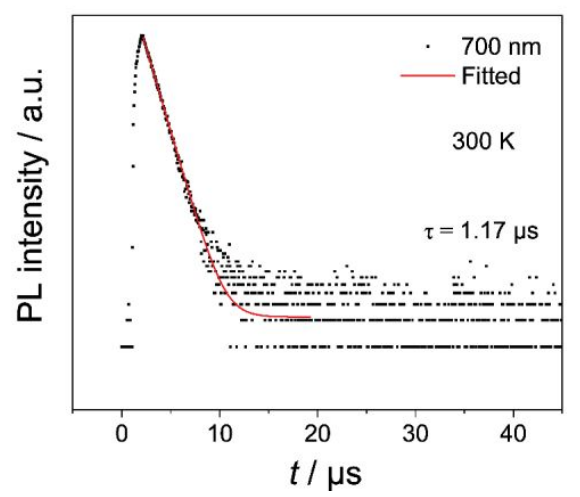

(b)

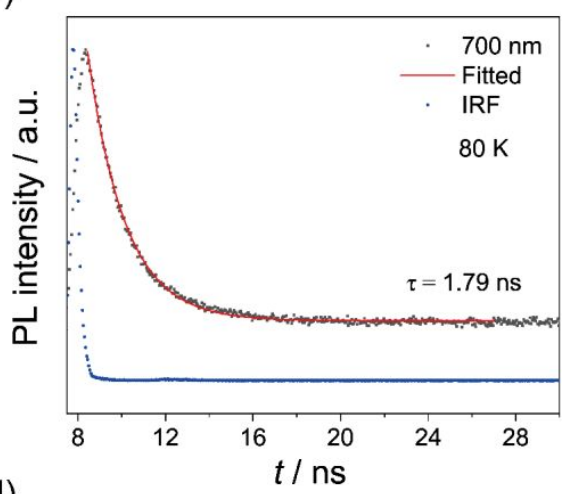

(d)

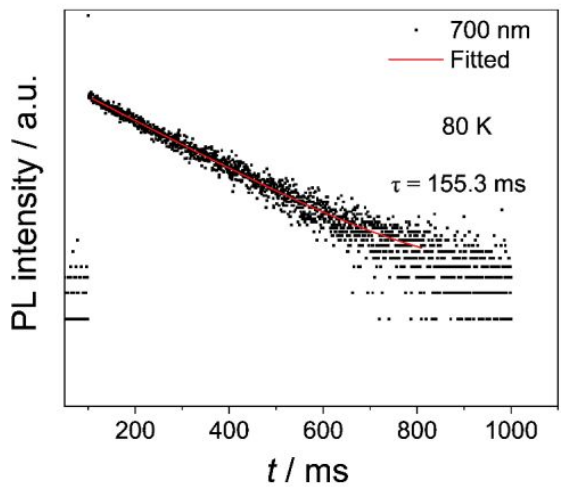

Figure S11. PL decay curves and fitted curves of emission peaks near $700 \mathrm{~nm}$ of $\mathrm{Y}_{3} \mathrm{~N} @ \mathrm{C}_{80}$ at (a) $300 \mathrm{~K}$ and (b) $80 \mathrm{~K}$ for prompt lifetime, as well as emission peaks near $700 \mathrm{~nm}$ of $\mathrm{Y}_{3} \mathrm{~N} @ \mathrm{C}_{80}$ at (c) $300 \mathrm{~K}$ and (d) $80 \mathrm{~K}$ for delayed lifetime.

(a)

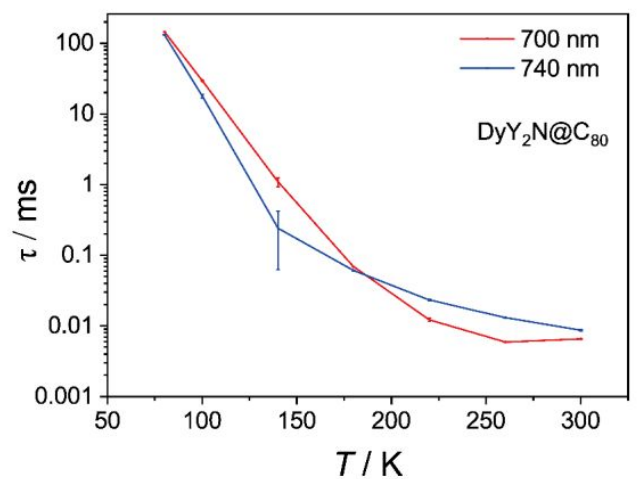

(b)

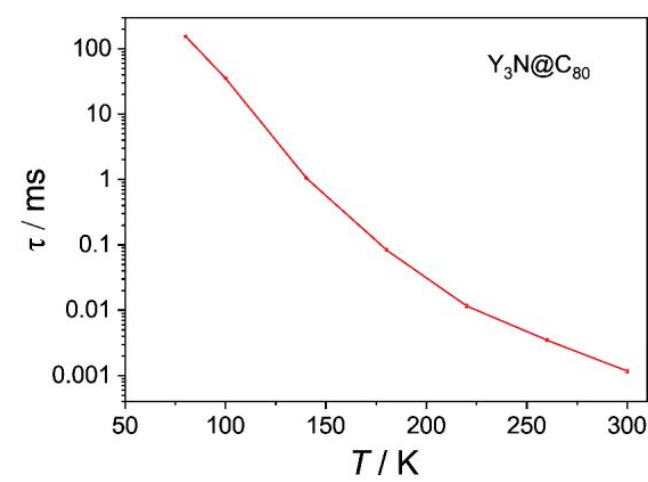

Figure S12. Logarithmic scale of decay lifetimes of (a) Dy $\mathrm{Y}_{2} \mathrm{~N} @ \mathrm{C}_{80}$ and (b) $\mathrm{Y}_{3} \mathrm{~N} @ \mathrm{C}_{80}$ at varied temperatures. 
(a)

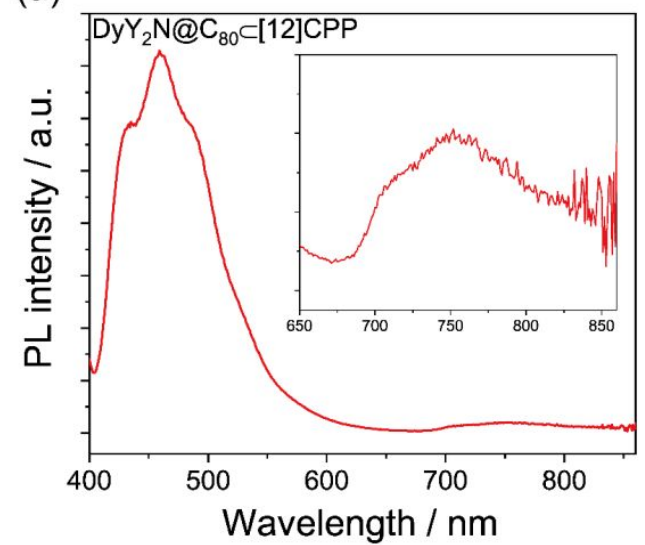

(b)

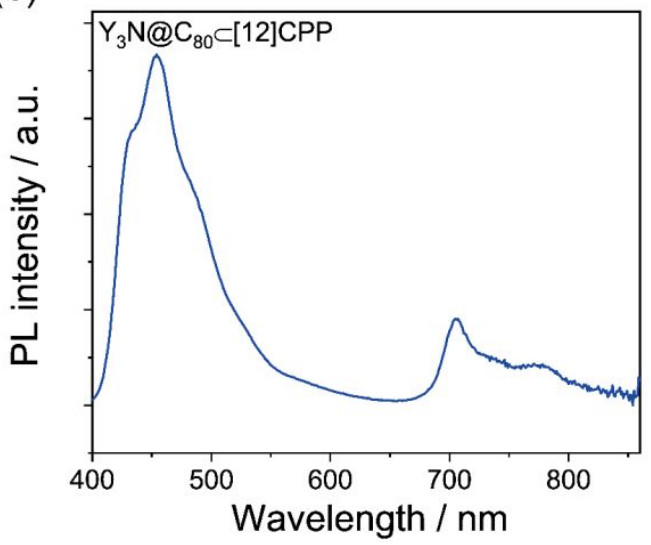

Figure S13. Photoluminescence spectra of (a) $\mathrm{DyY}_{2} \mathrm{~N} @ \mathrm{C}_{80} \subset[12] \mathrm{CPP}$, inset shows the magnified spectrum from 650-860 nm, (b) $\mathrm{Y}_{3} \mathrm{~N} @ \mathrm{C}_{80} \subset[12] \mathrm{CPP}$ degassed films at room temperature $\left(\lambda_{\mathrm{ex}}=\right.$ $350 \mathrm{~nm})$.

(a)

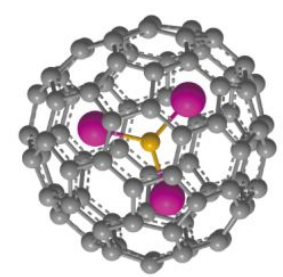

(b)

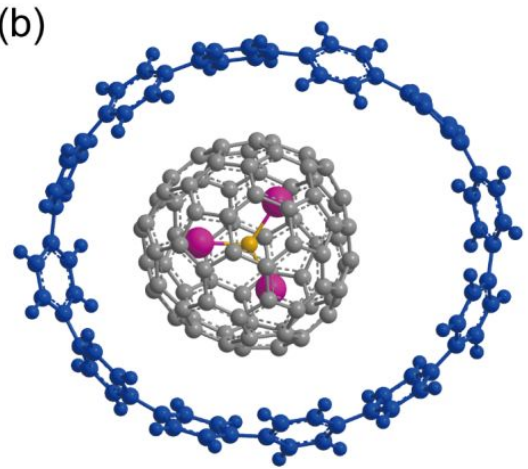

(c)

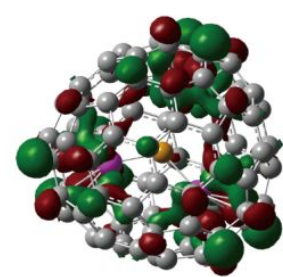

$-3.05 \mathrm{eV}$

진 $2.55 \mathrm{eV}$

$-5.60 \mathrm{eV}$

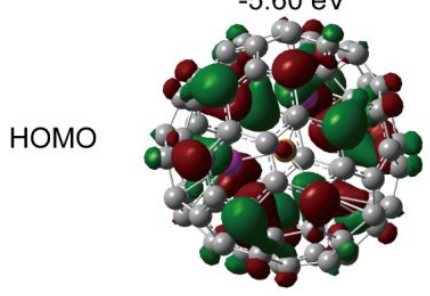

Figure S14. Optimized structures of (a) $\mathrm{Y}_{3} \mathrm{~N} @ \mathrm{C}_{80}$ and (b) $\mathrm{Y}_{3} \mathrm{~N} @ \mathrm{C}_{80} \subset[12] \mathrm{CPP}$. (c) Energy levels of the frontier orbitals of $\mathrm{Y}_{3} \mathrm{~N} @ \mathrm{C}_{80}$. (All calculations were performed at $\mathrm{B} 3 \mathrm{LYP} / 6-31 \mathrm{G}^{*} \sim \mathrm{SDD}$ level) 